\title{
Studies on the Fatty Acid Composition of some Salmonellas
}

\author{
By M. J. MODAK, S. NAIR AND A. VENKATARAMAN \\ Department of Biochemistry and Nutrition, Haffkine Institute, Bombay-12, India
}

(Accepted for publication 17 October 1969)

\begin{abstract}
SUMMARY
The available data on the fatty acid composition of Salmonella organisms is meagre and incomplete; the present work indicates that the three organisms examined have fatty acids ranging from $\mathrm{C}_{12}$ to $\mathrm{C}_{22}$ in their lipids. Changes in the growth medium may be responsible not only for quantitative differences but also for qualitative changes in the fatty acid spectrum of neutral compounds as well as phospholipids. The organisms can become avirulent possibly through fatty acid alterations of an endotoxin molecule.
\end{abstract}

\section{INTRODUCTION}

The development of our knowledge of bacterial lipids began with the work of R. J. Anderson on the tubercle bacilli in 1920. This work was continued for over 30 years and was concerned with the isolation and characterization of the bacterial fatty acids (including the complex mycolic acid), phosphatides and glycolipids. It is now known that the infective unit or endotoxin in many bacterial species has lipid as one of its constituents. In the early days, researches were mainly directed towards the study of the lipids of Gram-positive organisms which contain more than $15 \%$ lipid. Gram-negative organisms having lesser amounts of lipid (below I0\%) are now studied to achieve a certain evaluation of the taxonomic approach towards the differences between Gram-positive and Gram-negative organisms. Some results have been obtained in that the Gram-negative organisms have a high proportion of evennumbered saturated and unsaturated acids and odd-numbered cyclic acids; while the Gram-positive organisms have high amounts of the saturated odd-numbered branchchain acids and relatively low amounts of the straight-chain saturate acids. The occurrence of some unusual fatty acids in the microbial lipids has also stimulated efforts to correlate these lipid molecules with virulence and disease (O'Leary, I962; Neilson, 1966). Several organisms have been investigated for their fatty acid and lipid composition (Kates, I964, 1966). With the availability of thin-layer and gasliquid chromatography, rapid and sensitive techniques have become available for otherwise cumbersome lipid work. Although gas chromatographic methods alone cannot be used for the identification of these components, tentative identifications can be made and used as taxonomic criteria (Abel, Deschmertzing \& Peterson, 1963; Asselineau, 196I ; Henis, Goult \& Alexander, 1966; Steinhauer, Flentge \& Lechowich, 1967). Differences in the cultural conditions have been shown to be responsible for the changes in the fatty acid composition by many workers (Kates, Kuchner \& Janes, 1962; Marr \& Ingraham, 1962; Gavin \& Umbreit, I965; Divakaran \& Modak, I968). As regards Salmonella, not much information on the lipid composition is available 
except for a few reports by Cmelik (1952, 1953, I954, I955), MacFarlane (I962) and Gray (I962). The present work was to study the lipid composition of three strains of Salmonella and to see the variations, if any. A fatty-acid analyses of the phospholipid and neutral lipid fractions after separation on kieselgel-G has also been included.

\section{METHODS}

The cultures of Salmonella typhi (TY 2 strain), $S$. paratyphi $A$ and $S$. paratyphi $B$ were supplied by the Bacteriology Department of this Institute (these strains are used for the production of TAB vaccine). The bacteria were grown in $250 \mathrm{ml}$. Erlenmeyer flasks containing $50 \mathrm{ml}$. nutrient broth or defined medium (Modak, Nair \& Venkataraman, I968) on a rotary shaker (I00 rev./min.) for I $8 \mathrm{hr}$. The cell-mass after centrifugation at $10,000 \mathrm{rev} . / \mathrm{min}$. in the cold was washed with cold saline and dried in vacuum over $\mathrm{KOH}$.

Lipid extraction. Weighed amounts of the dried bacteria (about $500 \mathrm{mg}$.) were suspended in $30 \mathrm{ml}$. of chloroform + methanol in a $50 \mathrm{ml}$. beaker and subjected to ultrasonic disintegration for $30 \mathrm{~min}$. at maximum power (MSE ultrasonic disintegrator). The bacterial residue after centrifugation was once again extracted overnight with the solvent mixture at $30^{\circ}$. The combined extracts were filtered through a microsinter glass funnel and the non-lipid contaminants and methanol removed by saline washing as described by Folch, Lees \& Sloane-Stanley (1957). The chloroform+ methanol was distilled off under a gentle stream of nitrogen and the $\%$ lipid on dry weight basis calculated. The lipid extracts were divided into two parts. One part was used for the gross fatty acid pattern, while the other portion was applied on kieselgel-G for the separation of phospholipid and neutral lipid fraction. The kieselgel-G (E. Merck) was activated by heating to $105^{\circ}$ for $\mathrm{I} 8 \mathrm{hr}$ before use (for adsorption). Neutral lipids were first eluted with chloroform, while the phospholipid was eluted with methanol. The individual fractions of these lipids were concentrated under nitrogen and transmethylated as described below.

Preparation of methyl esters. Fatty acids from total lipid, neutral lipid and phospholipid were transesterified directly as described by Peterson, Deschmertzing \& Abel (I962) and Morrison \& Smith (1964) by boiling the lipids for $5 \mathrm{~min}$. in $5 \mathrm{ml}$. of $10 \%$ boron trifluoride in methanol (Applied Science Laboratories) followed by the addition of $3 \mathrm{ml}$. normal saline and extraction with ether. The solvent phase was evaporated under nitrogen.

Hydrogenation and bromination of unsaturated methyl esters. An apparatus like that described by Brian \& Gardner (1968) was used. About $5 \mathrm{mg}$. samples of methyl esters of fatty acids were taken up in $20 \mathrm{ml}$. of ethyl acetate into a $50 \mathrm{ml}$. Quick-Fit flask and platinum catalyst (200 mg. of $5 \%$ platinum oxide on charcoal) added. The flask was connected to the hydrogen source (a cylinder) and the contents kept stirred with a magnetic stirrer, after flushing with hydrogen. When hydrogen uptake ceased (60 min.) the catalyst was filtered off and the methyl esters dried under nitrogen. A portion of this hydrogenated sample was used for gas-liquid chromatographic analysis while the rest was used for bromination at $50^{\circ}$ under nitrogen ( $\mathrm{I}: 5$ bromine solution in ether) as described by Brian \& Gardner (I968). Bromination was necessary to break the cyclic acids which were converted to the straight chain variety.

Gas-liquid chromatography (g.l.c.). All g.l.c. work was done with a Panchromatograph 
Table I. Fatty acid composition of salmonellas (gross pattern)

\begin{tabular}{|c|c|c|c|c|c|c|}
\hline \multirow[b]{3}{*}{ Fatty acids } & \multicolumn{6}{|c|}{ Organism and growth medium } \\
\hline & \multicolumn{2}{|c|}{ S. typhi } & \multicolumn{2}{|c|}{ S. paratyphi $A$} & \multicolumn{2}{|c|}{ S. paratyphi $B$} \\
\hline & $\begin{array}{c}\text { Nutrient } \\
\text { broth }\end{array}$ & $\begin{array}{l}\text { Defined } \\
\text { medium }\end{array}$ & $\begin{array}{l}\text { Nutrient } \\
\text { broth }\end{array}$ & $\begin{array}{l}\text { Defined } \\
\text { medium }\end{array}$ & $\begin{array}{c}\text { Nutrient } \\
\text { broth }\end{array}$ & $\begin{array}{l}\text { Defined } \\
\text { medium }\end{array}$ \\
\hline Total lipid $(\%)$ & $5 \cdot 8$ & $5 \cdot 4$ & $5 \cdot 6$ & 4.9 & $5 \cdot 8$ & $5 \cdot 2$ \\
\hline $12: 0^{*}$ & $\mathrm{I} \cdot 5$ & $7 \cdot 6$ & $\mathrm{I} \cdot 6$ & $4 \cdot 6$ & II 7 & $3 \cdot 3$ \\
\hline $14: 0$ & $9 \cdot 0$ & $9 \cdot 0$ & $1 \mathrm{I} \cdot 5$ & $9 \cdot 2$ & $10 \cdot 3$ & $8 \cdot I$ \\
\hline $15: 0$ & 0.6 & 0.65 & 0.65 & 0.7 & 13.9 & 0.12 \\
\hline I6:0 & $49 \cdot 5$ & $60 \cdot 7$ & $56 \cdot 5$ & $52 \cdot 2$ & $30 \cdot 5$ & $25 \cdot 0$ \\
\hline I6:I & 0.6 & 0.7 & $1 \cdot 6$ & 0.9 & 4.8 & 0.13 \\
\hline $16: 2$ & - & - & - & - & - & 0.76 \\
\hline $17: 0$ & Trace & Trace & Trace & Trace & Trace & Trace \\
\hline I 7:0 (Cyc.) & 0.4 & $I \cdot O$ & $2 \cdot 0$ & $I \cdot 7$ & 0.37 & 0.27 \\
\hline I 8:0 & 0.28 & 0.53 & $0 \cdot 3$ & 0.25 & 0.95 & Trace \\
\hline $18: 1$ & $4 \cdot 4$ & $2 \cdot 3$ & $6 \cdot 1$ & $7 \cdot 1$ & $9 \cdot 5$ & $\mathrm{I} \cdot 3$ \\
\hline $18: 2$ & $11 \cdot 9$ & 6.0 & $7 \cdot 2$ & $6 \cdot 8$ & $7 \cdot 15$ & Trace \\
\hline $19: 0$ & - & - & - & 一 & - & $29 \cdot 9$ \\
\hline 19:0 (Cyc.) & $14 \%$ & $9 \cdot 2$ & $4 \cdot 3$ & $3 \cdot 8$ & $5 \cdot 28$ & 18.9 \\
\hline $20: 0$ & $2 \cdot 3$ & - & - & - & - & - \\
\hline $20: 4$ & Trace & 0.9 & $0 \cdot 85$ & 0.9 & Trace & $2 \cdot 3$ \\
\hline $21: 0$ & $14 \cdot 4$ & 0.9 & $7 \cdot 8$ & $11 \cdot 05$ & 5.05 & $5 \cdot 3$ \\
\hline $22: 0$ & $4 \cdot 7$ & $0 \cdot 7$ & 0.9 & 0.85 & 0.5 & $4 \cdot 7$ \\
\hline
\end{tabular}

Table 2. Fatty acid composition of neutral lipid of salmonellas

\begin{tabular}{|c|c|c|c|c|c|c|}
\hline \multirow[b]{3}{*}{ Fatty acids } & \multicolumn{6}{|c|}{ Organism and growth medium } \\
\hline & \multicolumn{2}{|c|}{ S. typhi } & \multicolumn{2}{|c|}{ S. paratyphi $A$} & \multicolumn{2}{|c|}{ S. paratyphi $B$} \\
\hline & $\begin{array}{l}\text { Nutrient } \\
\text { broth }\end{array}$ & $\begin{array}{l}\text { Defined } \\
\text { medium }\end{array}$ & $\begin{array}{c}\text { Nutrient } \\
\text { broth }\end{array}$ & $\begin{array}{l}\text { Defined } \\
\text { medium }\end{array}$ & $\begin{array}{l}\text { Nutrient } \\
\text { broth }\end{array}$ & $\begin{array}{l}\text { Defined } \\
\text { medium }\end{array}$ \\
\hline $\begin{array}{l}\text { Neutral lipid (\% } \\
\text { of the total lipid) }\end{array}$ & $37 \cdot 6$ & $42 \cdot 3$ & $38 \cdot 4$ & $44 \cdot 2$ & $35 \cdot 2$ & $40 \cdot 3$ \\
\hline I $2: 0^{*}$ & $2 \cdot 02$ & $I \cdot 57$ & $2 \cdot 5$ & $2 \cdot 4$ & $\mathrm{I} \cdot 03$ & $\mathrm{I} \cdot 08$ \\
\hline 14:0 & $5 \cdot 95$ & $1 I \cdot 0$ & $11 \cdot 3$ & $10 \cdot 2$ & $8 \cdot 95$ & 10.4 \\
\hline $15: 0$ & 0.2 & 0.7 & $I \cdot 38$ & 0.9 & 0.4 & $I \cdot \mathbf{I}$ \\
\hline I6:0 & $62 \cdot 5$ & $37 \cdot 5$ & $23 \cdot 8$ & $30 \cdot 5$ & $37 \cdot 4$ & $22 \cdot 2$ \\
\hline I6: I & $4 \cdot 2$ & $0 \cdot I$ & $8 \cdot 95$ & $2 \cdot 3$ & Trace & $26 \cdot 5$ \\
\hline $17: 0$ & Trace & Trace & 0.1 & - & 0.4 & 0.7 \\
\hline I7:o (Cyc.) & $\mathbf{I} \cdot 68$ & $0 \cdot 2$ & $2 \cdot 65$ & $3 \cdot 2$ & $3 \cdot 75$ & 0.99 \\
\hline $18: 0$ & $0 \cdot 13$ & 3.9 & 0.07 & 0.9 & $0 \cdot 26$ & 0.69 \\
\hline I 8:I & $8 \cdot 75$ & 0.9 & $28 \cdot 0$ & $22 \cdot 0$ & 0.26 & $24 \cdot 4$ \\
\hline I $8: 2$ & - & $17 \cdot 6$ & - & 10.0 & $6 \cdot 25$ & - \\
\hline 19:o (Сyc.) & $5 \cdot 7$ & - & $9 \cdot 65$ & $10 \cdot 2$ & $15 \cdot 5$ & $3 \cdot 4$ \\
\hline $20: 0$ & $5 \cdot 9$ & $16 \cdot 2$ & $6 \cdot 4$ & $2 \cdot 4$ & - & - \\
\hline $20: 4$ & - & - & $2 \cdot 57$ & $x \cdot 6$ & - & 一 \\
\hline $21: 0$ & $2 \cdot 5$ & $6 \cdot 35$ & $3 \cdot 4$ & I I $\cdot 2$ & 3.55 & I $\cdot 79$ \\
\hline $22: 0$ & 0.37 & 0.47 & I. 54 & 0.9 & $3 \cdot 1$ & 0.5 \\
\hline
\end{tabular}

* The number preceding the colon designates the number of carbons;

the number following indicates the unsaturation. 
equipped with ${ }^{90} \mathrm{Sr}$ ionizing detector. The g.l.c. conditions were: column packing, I5\% ethylene glycol succinate (EGS) polyester on chromosorb W (80 to $100 \mathrm{mesh}$ ); column length $5 \mathrm{ft}$. ( $\mathrm{I} 18 \mathrm{~cm}$.) $\times 4 \mathrm{~mm}$. internal diameter; column temperature $184^{\circ}$; detector temperature $210^{\circ}$; argon flow rate 30 to $60 \mathrm{ml} . / \mathrm{min}$.

Identification of the g.l.c. peaks. Identification of the g.l.c. peaks was done by: (i) comparing the retention time with standard compounds (Sigma) of known purity; (ii) analysis of g.l.c. results before and after hydrogenation to fix the identity of unsaturated fatty acid methyl esters; (iii) plotting retention times against chain length relative to methyl palmitate and determining the chain length of the unknown peak from the curve, (iv) comparing the retention times relative to methyl palmitate and stearate to those reported in literature (Brian \& Gardner, I968). No differentiation was attempted as regards the position of the double bonds. The percentage composition was calculated by the triangulation method.

Table 3. Fatty acid composition of phospholipid of salmonellas

\begin{tabular}{|c|c|c|c|c|c|c|}
\hline \multirow[b]{3}{*}{ Fatty acids } & \multicolumn{6}{|c|}{ Organism and growth medium } \\
\hline & \multicolumn{2}{|c|}{ S. typhi } & \multicolumn{2}{|c|}{ S. paratyphi $A$} & \multicolumn{2}{|c|}{ S. paratyphi B } \\
\hline & $\begin{array}{l}\text { Nutrient } \\
\text { broth }\end{array}$ & $\begin{array}{l}\text { Defined } \\
\text { medium }\end{array}$ & $\begin{array}{l}\text { Nutrient } \\
\text { broth }\end{array}$ & $\begin{array}{l}\text { Defined } \\
\text { medium }\end{array}$ & $\begin{array}{l}\text { Nutrient } \\
\text { broth }\end{array}$ & $\begin{array}{l}\text { Defined } \\
\text { medium }\end{array}$ \\
\hline $\begin{array}{l}\text { Phospholipid ( } \% \\
\text { of the total lipid) }\end{array}$ & $50 \cdot 0$ & $45 \cdot 6$ & $49 \cdot 8$ & $44 \cdot 2$ & $52 \cdot 7$ & $40 \cdot 2$ \\
\hline 10:0* & - & - & - & - & - & 3.75 \\
\hline $12: 0$ & 0.33 & I I I9 & 6.0 & $5 \cdot 8$ & $2 \cdot 27$ & $5 \cdot 25$ \\
\hline I4:0 & $6 \cdot 6$ & $7 \cdot 15$ & $12 \cdot 0$ & $13 \cdot 2$ & $7 \cdot 72$ & $5 \cdot 25$ \\
\hline I $5: 0$ & $\mathbf{I} \cdot 39$ & $5 \cdot 6$ & $5 \cdot 0$ & $6 \cdot I$ & $27 \cdot 2$ & $6 \mathrm{I} \cdot 0$ \\
\hline $16: 0$ & $56 \cdot 5$ & $51 \cdot 0$ & $68 \cdot 0$ & $62 \cdot 0$ & $38 \cdot 5$ & 0.05 \\
\hline I6:I & $2 \cdot 38$ & - & - & 0.9 & $7 \cdot 1$ & $0 \cdot 1$ \\
\hline I6:2 & 0.69 & 0.67 & -- & - & - & $\mathrm{I} \cdot 2$ \\
\hline $17: 0$ & $I \cdot 66$ & Trace & - & - & 一 & $I \cdot 67$ \\
\hline 17:0 (Cyc.) & Trace & Trace & Trace & Trace & Trace & Trace \\
\hline I8:0 & $12 \cdot 3$ & $6 \cdot 12$ & $2 \cdot 3$ & 0.9 & $I \cdot 79$ & $4 \cdot 46$ \\
\hline I 8: I & $6 \cdot 72$ & $9 \cdot 35$ & $4 \cdot I$ & $3 \cdot 2$ & $3 \cdot 0$ & $5 \cdot 25$ \\
\hline $18: 2$ & $3 \cdot 57$ & $I \cdot 52$ & $2 \cdot 5$ & - & - & - \\
\hline $19: 0$ & - & - & - & - & $4 \cdot 3$ & - \\
\hline 19:0 (Cyc.) & Trace & Trace & Trace & $10 \cdot 8$ & Trace & $7 \cdot 2$ \\
\hline 20:0 & Trace & Trace & Trace & Trace & $\mathbf{I} \cdot 57$ & $4 \cdot 8$ \\
\hline $20: 4$ & - & $5 \cdot 6$ & - & Trace & $I \cdot 5$ & Trace \\
\hline 2I:0 & - & $7 \cdot 6$ & Trace & Trace & 3.0 & $4 \cdot 2$ \\
\hline $22: 0$ & $I \cdot 49$ & $4 \cdot 24$ & Trace & Trace & 一 & $4 \cdot 8$ \\
\hline
\end{tabular}

* The number preceding the colon designates the number of carbons; the number following indicates the unsaturation.

\section{RESULTS}

Gross fatty acid composition. The results of the gross fatty acid analyses are given in Table $\mathrm{I}$. More than $60 \%$ of the total fatty acids were $\mathrm{C}_{16}$ (palmitic) and the lower acids, palmitic acid being maximum in all the cases. Though there were quantitative differences, all the three organisms showed more or less similar spectra of fatty acids ranging from $\mathrm{C}_{12}$ to $\mathrm{C}_{22}$. The change in the growth medium did not affect the spectrum, except in the case of Salmonella paratyphi $B$ grown in defined medium where $C_{19}$ acid 
appeared in appreciable amounts. This acid was absent in $S$. typhi and S. paratyphi $A$ and also in $S$. paratyphi $B$ grown in nutrient broth. Similarly, $\mathrm{C}_{20}$ acid was present only in $S$. typhi grown in nutrient broth. The major acids present included $\mathrm{C}_{14}, \mathrm{C}_{16}$, $\mathrm{C}_{21}$ normal saturated, $\mathrm{C}_{18}$ and $\mathrm{C}_{18: 2}$ normal unsaturated and $\mathrm{C}_{19}$ cyclic.

Fatty acid composition of neutral lipids. The neutral lipid fractions of the three organisms were qualitatively similar except for the absence of $\mathrm{C}_{20}$ from Salmonella paratyphi $B$. Major acids are $\mathrm{C}_{16}, \mathrm{C}_{16: 1}, \mathrm{C}_{18: 1}, \mathrm{C}_{19}$ cyclic and $\mathrm{C}_{20}$. In addition, detectable amounts of $\mathrm{C}_{17}$ cyclic and $\mathrm{C}_{21}$ were also noted (Table 2).

Fatty acids of phospholipids. The major acid in all the three organisms was palmitic acid; high amounts of $\mathrm{C}_{15}$ acid were noted in the phospholipids of Salmonella paratyphi $B . \mathrm{C}_{19}$ cyclic acid was absent (Table 3 ). A peculiar observation of these analyses was that in $S$. typhi grown on defined medium, $\mathrm{C}_{20: 4}$ and $\mathrm{C}_{21}$ "were present to the extent of $5 \%$, though these acids were not noted in the phospholipids of $S$. typhi grown in nutrient broth. $\mathrm{C}_{17}$ acid was detected in traces. More than $80 \%$ of the fatty acids of the total phospholipids of $S$. paratyphi $A$ were palmitic $\left(\mathrm{C}_{\mathbf{1 6}}\right)$ and lower.

\section{DISCUSSION}

Cmelik (1952, 1953, 1954, 1955) investigated the lipids of several members of the Enterobacteriacea. The total lipid content ranged from I. 5 to $10 \%$ of which 50 to $90 \%$ was neutral lipid. Fatty acids were reported as being mainly palmitic and $\mathrm{C}_{18}$ monoenoic acids. As against this report, MacFarlane (I962) found a lipid content of $5.6 \%$ in Salmonella typhimurium of which only I $4 \%$ was neutral lipid while the rest was phosphatidyl ethanolamine. The fatty acids consisted mainly of palmitic $\left(\mathrm{C}_{16}\right)$, oddnumbered $\mathrm{C}_{17}$ and $\mathrm{C}_{19}$ cyclopropane, $\mathrm{C}_{16}$ and $\mathrm{C}_{18}$ monoenoic acids with small amounts of myristic and stearic acids (Macfarlane, I962; Gray, 1962). Our results agree with those of Cmelik in that the neutral lipid content of the three Salmonella strains examined in the present study was around $40 \%$ and palmitic acid was the major fatty acid. Our values of total lipid are in good agreement with those of MacFarlane, for $S$. typhimurium. The fatty acid spectrum we found differs from MacFarlane's report in having lesser amounts of monoenoic hexadecanoic $\left(C_{16: 1}\right)$ and cyclic $C_{17}$ acids. Stearic acid was below I \% while myristic acid was in quite appreciable quantities (about $10 \%$ ). Amounts of $\mathrm{C}_{18: 2}$ and $\mathrm{C}_{21}$ have been noted in this study which were not detected by earlier workers.

Data on the fatty acid composition of neutral and phospholipids are not available in the literature for comparison. The neutral lipid we found, showed a similar spectrum of fatty acids to that of total lipid but seemed to be much affected by the change in the medium for growth. This effect is seen more prominently for Salmonella paratyphi $B$. The values for palmitic, palmito-oleic $\left(\mathrm{C}_{16: 1}\right)$ and monoenoic-octadecanoic $\left(\mathrm{C}_{18: 1}\right)$ may be cited as an example of this; with $S$. typhi and $S$. paratyphi $A$ this effect was seen in $\mathrm{C}_{16}, \mathrm{C}_{18: 1}$ and $\mathrm{C}_{20}$ acids. Salmonella paratyphi $A$ contained higher amounts of monoenoic stearic acid as compared with the other two strains.

When the fatty acid composition of the phospholipid was examined, it was seen that Salmonella paratyphi $A$ contained the highest concentration of palmitic acid (62 to $68 \%$ ). Noticeable amounts of stearic acid were detected in this fraction. Cyclic and straight chain $\mathrm{C}_{18}$ were absent. Arachidonic $\left(\mathrm{C}_{20: 4}\right)$ acid was present in $S$. typhi $(5 \cdot 4 \%)$ and $S$. paratyphi $B(\mathrm{I} \cdot 5 \%)$ and was absent in $S$. paratyphi $A$. The phospho- 
lipid isolated from $S$. paratyphi $B$ grown in defined medium showed an unusually high content of $\mathrm{C}_{15}(6 \mathrm{I} \%)$ and an extremely small amount of palmitic acid.

Thus, though fatty acid composition of the total, neutral and phospholipids of the three organisms were examined quantitatively and in some instances qualitatively, nothing definite could be inferred about variations observed in the same organism when subjected to different growth medium. It is known that temperature, growth medium and growth conditions can alter the fatty acid composition (Kates, 1964). Hence such quantitative alterations in the fatty acid composition of the bacteria grown in the defined medium and nutrient broth were to be expected. However, the changes observed were not only quantitative but also qualitative, i.e. the introduction or elimination of one or more fatty acids in the original profiles. On the basis of the above observation, it may be suggested that the loss of virulence in the Salmonella or other such pathogenic species when grown on different media or transferred from natural medium to defined medium might be the result of the fatty acid alterations.

One of us (M. J. M.) gratefully acknowledges the receipt of Haffkine Institute Diamond Jubilee Research Fellowship. We are also grateful to Dr (Miss) D. H. Shah and Dr P. G. Satyaswaroop of Radiation Medicine Centre, Bhabha Atomic Research Centre, Bombay for the kind help rendered in g.l.c. analysis.

\section{REFERENCES}

Abel, K., Deschmertzing, H. \& Peterson, J. I. (1963). Classification of micro-organisms by analysis of chemical composition. I. Feasibility of utilizing gas chromatography. Journal of Bacteriology 85, 1039 .

AsselineaU, J. (I96I). Sur quelques applications de la chromatographie en phase gazeuse a l'étude d'acides gras bactériens. Annales de l'Institut Pasteur, Paris 100, 109.

BRIAN, B. L. \& GARDNER, E. W. (I968). Fatty acids from Vibrio cholerae lipids. Journal of Infectious Diseases I18, 47.

CMELIK, S. (1952). Bacterial lipids. I. The lipids of Salmonella typhosa. Hoppe-Seyler's Zeitschrift für Physiologische Chemie 290, 146.

CMELIK, S. (I953). Bacterial lipids. II. The lipids of Salmonella ballerup. Hoppe-Seyler's Zeitschrift für Physiologische Chemie 293, 222.

CMELIK, S. (1954). Lipids and virulence in typhoid bacteria. Experientia ro, 372.

CMELIK, S. (1955). Bacterial lipids. V. Lipids of typhoid bacteria. Hoppe-Seyler's Zeitschrift für Physiologische Chemie 299, 227.

Divakaran, P. \& Modak, M. J. (1968). Fatty acid composition of mycelium of Penicillium chrysogenum grown in different carbohydrates as a sole source of carbon. Experientia 24, I 102.

Folch, J., Lees, M. \& Sloane-Stanley, G. H. (1957). A simple method for the isolation and purification of total lipids from animal tissues. Journal of Biological Chemistry 226, 497.

GAVIN, J. J. \& UMBREIT, W. W. (I965). Effect of biotin on fatty acid distribution in Escherichia coli. Journal of Bacteriology 89, 437.

GRAY, G. M. (1962). The cyclopropane ring fatty acids of Salmonella typhimurium. Biochimica et Biophysica Acta 65, 135 .

Henis, Y., Goult, J. R. \& Alexander, M. (I966). Detection and identification of bacteria by gas chromatography. Applied Microbiology 14, 513.

KASAI, N. (1966). Chemical studies on the lipid component of endotoxin with special emphasis on its relation to biologic activity. Annals of the New York Academy of Sciences 133, 486.

KATES, M. (1964). Bacterial lipids. Advances in Lipid Research 2, I7.

KATES, M. (1966). Biosynthesis of lipids in micro-organisms. Annual Review of Microbiology $20,13$.

Kates, M. Kuchner, P. J. \& JANES, A. T. (1962). The lipid composition of Bacillus cereus as influenced by the presence of alcohol in the culture medium. Canadian Journal of Biochemistry and Physiology 40, 83 . 
MacFarlane, M. G. (1962). Lipid component of Staphylococcus aureus and Salmonella typhimurium. Biochemical Journal 92, 40 p.

MARR, A. G. \& INGRAHAM, J. M. (I962). Effect of temperature on the composition of fatty acids in Escherichia coli. Journal of Bacteriology 84, $\mathrm{I} 260$.

Modak, M. J., Nair, S. \& Venkataraman, A. (1968). Biochemistry of the Salmonella. IV. Metabolism of $\left[\mathrm{I}^{-14} \mathrm{C}\right]$ xylose by $S$. typhi, S. paratyphi $A$ and $S$. paratyphi $B$ under stationary conditions of their growth. Indian Journal of Pathology and Bacteriology II, 24.

Morrison, W. R. \& SMITH, L. M. (I964). Preparation of fatty acid methyl esters and dimethylacetals from lipids with boron fluoride-methanol. Journal of Lipid Research $5,600$.

NerLson, H. S. JUN. (1966). Variation in lipid content of strains of Histoplasma capsulatum exhibiting different virulent properties for mice. Journal of Bacteriology 91, 273.

O'Leary, W. M. (I962). Fatty acids of bacteria. Bacteriological Reviews 26, 429.

Peterson, J. I., Deschmertzing, H. \& Abel, K. (1962). Transesterification of lipids with boron trichloride. Proceedings of the 142 nd Meeting of the American Chemical Society p. $2 \mathrm{IB}$.

Steinhauer, J. E., Flentge, R. L. \& Lechowich, R. V. (I967). Lipid pattern of selected microorganisms as determined by gas-liquid chromatography. Applied Microbiology 15, 826 . 